\title{
Polymorphisms in the XPC gene and gastric cancer susceptibility in a Southern Chinese population
}

\section{Rui-Xi Hua, 1,2,* Zhen-Jian Zhuo, 3,* Guo-Ping Shen,' Jinhong Zhu, ${ }^{4}$ Shao-Dan Zhang,' Wen-Qiong Xue,' Xi-Zhao Li,' Pei-Fen Zhang,' Jing $\mathrm{He},{ }^{1,5}$ Wei-Hua Jia' \\ 'Department of Experimental Research, Sun Yat-sen University Cancer Center, State Key Laboratory of Oncology in South China, Collaborative Innovation Center for Cancer Medicine, ${ }^{2}$ Department of Oncology, The First Affiliated Hospital of Sun Yat-sen University, ${ }^{3}$ Department of Traditional Chinese Medicine Research, Guangdong Province Key Laboratory of Pharmacodynamic Constituents of TCM and New Drugs Research, College of Pharmacy, Jinan University, Guangdong, ${ }^{4}$ Department of Laboratory Medicine and Molecular Epidemiology Laboratory, Harbin Medical University Cancer Hospital, Heilongjiang, ${ }^{5}$ Department of Pediatric Surgery, Guangzhou Institute of Pediatrics, Guangzhou Women and Children's Medical Center, Guangzhou Medical University, Guangdong, People's Republic of China \\ *These authors contributed equally to this work}

Correspondence: Jing $\mathrm{He}$

Department of Pediatric Surgery, Guangzhou Institute of Pediatrics, Guangzhou Women and Children's Medical Center, Guangzhou Medical University, 9 Jinsui Road, Guangzhou 510623, Guangdong, People's Republic of China

$\mathrm{Tel} / \mathrm{fax}+862038076560$

Email hj02021313@163.com

Wei-Hua Jia

Department of Experimental Research, Sun Yat-sen University Cancer Center, State Key Laboratory of Oncology in South China, Collaborative Innovation Center for Cancer Medicine, 65I Dongfeng Road East, Guangzhou 510060, Guangdong, People's Republic of China

Tel +86 2087342327

Fax +862087343392

Email jiaweih@mail.sysu.edu.cn
This article was published in the following Dove Press journal:

OncoTargets and Therapy

7 September 2016

Number of times this article has been viewed

Abstract: Previous studies have reported that $X P C$ gene polymorphisms may modify the individual susceptibility to gastric cancer. In this case-control study with a total of 1,142 cases and 1,173 controls, four potentially functional polymorphisms were genotyped in the $X P C$ gene (rs2228001 A >C, rs2228000 C > T, rs2607775 C > G, and rs1870134 G >C) by Taqman assays and their associations were analyzed with the risk of gastric cancer in a Southern Chinese population. No significant association between any of XPC polymorphisms and gastric cancer risk was detected except for a borderline association with the rs2228000 CT/TT genotype (crude odds ratio $=0.86,95 \%$ confidence interval $=0.73-1.02, P=0.088$ ) when compared to the rs $2228000 \mathrm{CC}$ genotype. Further stratified analysis revealed that the protective effect of rs $2228000 \mathrm{CT} / \mathrm{TT}$ on the risk of gastric cancer was only significant among subjects older than 58 years. In summary, results indicated that genetic variations in XPC gene may play a weak effect on gastric cancer susceptibility in Southern Chinese population, which warrants further confirmation in larger prospective studies with different ethnic populations.

Keywords: gastric cancer, $X P C$, polymorphism, DNA repair, genetic susceptibility

\section{Introduction}

Gastric cancer is the fifth most common cancer and the third leading cause of cancer-related deaths worldwide. Although a marked decrease in incidence and mortality rates has been observed in most industrialized countries, the incident rate remains high in Eastern Asia, Eastern Europe, and South America. ${ }^{1}$ In People's Republic of China, the survival of gastric cancer is poor. Although remarkable achievements have been made in surgical treatments, targeted therapies, and chemotherapies, the overall 5-year survival rate for gastric cancer is relatively low, $\sim 27.4 \%$. As a result, People's Republic of China still carries a substantial burden of gastric cancer. ${ }^{2}$ The initiation and development of gastric cancer is a multistep and multifactorial process influenced by environmental, genetic, and epigenetic factors. ${ }^{3}$ Epidemiological studies have revealed that Helicobacter pylori infection, nutritional deficiencies, low fresh vegetable and fruit intake, smoking, drinking, and high body mass index may contribute to the etiology of gastric cancer. ${ }^{4-7}$ However, most individuals exposed to these environmental risk factors actually never develop gastric cancer in their lifetime, suggesting the indispensible role of genetic factors in gastric carcinogenesis. $^{8-12}$

DNA repair system plays a vital role in maintaining the stability and integrity of human genome and normal cellular functions. To date, at least five known major DNA repair pathways consisting of $>130$ genes are validated..$^{13}$ Nucleotide excision repair 
(NER) pathway, one of the most versatile DNA repair mechanisms, is responsible for removing a wide variety of DNA lesions, such as alkylating damage, bulky adducts, crosslinks, oxidative DNA damage, and thymidine dimers. ${ }^{13,14}$ In humans, defects in the NER pathway can result in a rare autosomal recessive disease, xeroderma pigmentosum (XP), which is characterized by extreme susceptibility to ultraviolet and a high predisposition to sunlight-induced skin cancer. ${ }^{15}$ Thus far, at least eight complementation groups (XPA to $\mathrm{G}$ and ERCC1), which limit the rate of NER mechanism, have been identified. ${ }^{16}$

The $X P C$ gene is one of the eight key genes in the NER pathway. Its protein product plays an important role in global genomic NER, especially in damage recognition, open complex formation, and reparation. ${ }^{17} \mathrm{XPC}$ tightly binds to HR23B (also known as ultraviolet excision repair protein RAD23 homolog B) to form the XPC-HR23B complex, which functions as an early damage detector and a molecular matchmaker for recruitment of the transcription factor IIH (including two helicases: ERCC3/XPB and ERCC2/XPD) to the damaged DNA during the global genomic NER. ${ }^{17,18}$

To date, 2,582 polymorphic variants in the XPC gene have been identified (http://www.ncbi.nlm.nih.gov/projects/ SNP). A multitude of studies have been performed to investigate the association between the $X P C$ polymorphisms and cancer risk. ${ }^{19-22}$ However, the association between $X P C$ gene polymorphisms and gastric cancer remains conflicting due to limited sample size and ethnic diversity. Therefore, it is essential to further assess the associations of potentially functional XPC polymorphisms with gastric cancer susceptibility. In this study, the current case-control study was conducted to better understand the associations between four functional single nucleotide polymorphisms (SNPs) of XPC gene and the risk of gastric cancer, consisting of 1,173 healthy controls and 1,142 gastric cancer patients.

\section{Materials and methods}

\section{Study population}

A total of 1,142 gastric cancer patients were enrolled between February 2002 and September 2013 from Sun Yat-sen University Cancer Center. Cases were eligible if they had newly diagnosed and histologically confirmed primary gastric cancer without undergoing radiotherapy and chemotherapy treatment. All 1,173 healthy controls without tumor and other diseases were randomly enrolled from Sihui city, Guangdong. All the research subjects were unrelated ethnic Han Chinese population from Southern China. They were interviewed face-to-face by specially trained professional interviewers and provided signed informed consent forms. The questions included demographic characteristics (eg, age and sex) and lifestyle habits (eg, smoking habits and alcohol drinking). Individuals who smoked $<1$ package of cigarettes every day but no more than a year were defined as nonsmokers, while those who drank alcohol less than once a week but no more than a year were defined as nondrinkers, as described earlier. ${ }^{9}$ With the permission of the subjects, $\sim 5 \mathrm{~mL}$ of venous blood sample was collected from each subject for genetic testing. In general, the response rates of both cases and controls were $>85 \%$. This study was approved by the institutional review board of Sun Yat-sen University Cancer Center.

\section{Selection of candidate SNPs and genotyping}

The potentially functional SNPs were selected by using the NCBI dbSNP database and SNPinfo (http://snpinfo.niehs. nih.gov/snpinfo/snpfunc.htm). The following criteria were applied: 1) the minor allele frequency reported in HapMap was $>5 \%$ for Chinese Han subjects; 2) putative functional potential SNPs, which might affect transcription activity or binding capacity of the microRNA-binding site; and 3) SNPs in low linkage disequilibrium with each other $\left(R^{2}<0.8\right)$. Based on the criteria, four potential functional SNPs (rs2228001 A $>$ C, rs2228000 C $>$ T, rs2607775 C $>$ G, and $\mathrm{rs} 1870134 \mathrm{G}>\mathrm{C}$ ) were selected.

Genomic DNA was extracted from blood samples using the Qiagen Blood DNA Mini Kit (Qiagen Inc., Valencia, CA, USA) according to the instructions of the manufacturer. Genotype analyses of all SNPs were performed by the Taqman real-time polymerase chain reaction method using a 7900 Sequence Detection System (Thermo Fisher Scientific, Waltham, MA, USA) as described previously. ${ }^{9}$ To achieve more reliable genotyping results, four duplicated positive controls and four negative controls without DNA template were loaded in each of 384-well plates. Genotyping was repeated on a random $10 \%$ of the samples, and the results were $100 \%$ concordant.

\section{Statistical analysis}

Chi-square test was used to compare the differences between cases and controls regarding demographic characteristics, smoking and drinking status, and SNP genotypes. Goodnessof-fit $\chi^{2}$ test was performed to test whether the genotype frequency distribution of each polymorphism in controls was in Hardy-Weinberg equilibrium. Odds ratios (ORs) and $95 \%$ confidence intervals (CIs) were calculated to estimate the associations between each SNP and gastric cancer risk, 
using univariate and multivariate logistic regression models. Further stratification analysis by age, sex, pack-years, smoking and drinking status, tumor sites, and TNM stages were also performed. All statistical analysis was performed using SAS software (version 9.1; SAS Institute Inc., Cary, NC, USA). A two-sided statistical significance level of 0.05 was chosen.

\section{Results}

\section{Population characteristics}

The clinical and demographic characteristics of the study population, consisting of 1,142 cases and 1,173 healthy controls, are summarized in Table 1 . No significant differences were observed between the cases and controls in term of sex $(P=0.393)$. However, the average age of cases were significantly higher than that of controls $(P<0.0001)$. The controls were more likely to be smokers and drinkers than the cases (both $P<0.0001$ ). Moreover, there was significant difference in the distributions of pack-years between

Table I Clinical and demographic characteristics of gastric cancer patients and cancer-free controls

\begin{tabular}{|c|c|c|c|}
\hline Variables & Case, n (\%) & Control, n (\%) & $P$-value ${ }^{a}$ \\
\hline All subjects & $\mathrm{I}, \mathrm{I} 42(100.0)$ & I,I $73(100.0)$ & \\
\hline Sex & & & 0.393 \\
\hline Male & $749(65.6)$ & $789(67.3)$ & \\
\hline Female & $393(34.4)$ & $384(32.7)$ & \\
\hline Age, years & $15-86$ & $16-80$ & $<0.000$ I \\
\hline Mean & $56.3 \pm 12.5$ & $45.2 \pm 11.6$ & \\
\hline$\leq 50$ & $334(29.3)$ & $789(67.3)$ & \\
\hline $5 I-60$ & $362(31.7)$ & $285(24.3)$ & \\
\hline $6 I-70$ & $312(27.3)$ & $73(6.2)$ & \\
\hline$>70$ & 134 (I I.7) & $26(2.2)$ & \\
\hline Smoking status & & & $<0.000$ I \\
\hline Never & $735(64.4)$ & $662(56.4)$ & \\
\hline Ever & $407(35.6)$ & $511(43.6)$ & \\
\hline Drinking status & & & $<0.0001$ \\
\hline No & $934(81.8)$ & $600(5 \mid .2)$ & \\
\hline Yes & $208(18.2)$ & $573(48.8)$ & \\
\hline Pack-years & & & $<0.0001$ \\
\hline 0 & $735(64.4)$ & $662(56.4)$ & \\
\hline$\leq 30$ & $272(23.8)$ & $383(32.7)$ & \\
\hline$>30$ & $135(1 \mid .8)$ & $128(10.9)$ & \\
\hline \multicolumn{4}{|l|}{ Sites } \\
\hline Cardia & $240(21.0)$ & - & \\
\hline Non-cardia & $902(79.0)$ & - & \\
\hline \multicolumn{4}{|l|}{ TNM stage } \\
\hline I & 140 (I2.3) & - & \\
\hline II & $329(28.8)$ & - & \\
\hline III & $456(39.9)$ & - & \\
\hline IV & $217(19.0)$ & - & \\
\hline
\end{tabular}

Note: ${ }^{2} T$ wo-sided chi-square test for distributions between gastric cancer cases and cancer-free controls. the cases and controls $(P<0.0001)$. Among gastric cancer patients, 21\% (240 cases) had gastric cardia adenocarcinoma, while 79\% (902 cases) had nongastric cardia adenocarcinoma. Regarding tumor stage, 140 (12.3\%), 329 (28.8\%), 456 (39.9\%), and 217 tumors (19\%) were classified as TNM stages I, II, III, and IV, respectively, according to the 7 th Edition of the American Joint Committee on Cancer. ${ }^{23}$

\section{Associations between XPC gene polymorphisms and gastric cancer risk}

The genotype distributions of the selected XPC gene polymorphisms in cases and controls and their associations with gastric cancer risk are summarized in Table 2. The genotype frequency distributions of all SNPs in the control subjects were in agreement with Hardy-Weinberg equilibrium. Variables including age, smoking, drinking, and pack-years were adjusted for in the subsequent multivariate logistic regression analyses. The logistic regression analysis showed that none of the four SNPs was associated with gastric cancer risk in homozygotes or heterozygotes after being adjusted for age, sex, smoking, and drinking status. When compared with CC genotypes, the rs $2228000 \mathrm{CT} / \mathrm{TT}$ genotypes were not associated with gastric cancer risk (crude $\mathrm{OR}=0.86,95 \% \mathrm{CI}=0.73-1.02, P=0.088)$, even after adjust ment for age, sex, smoking, and drinking status (adjusted $\mathrm{OR}=0.90,95 \% \mathrm{CI}=0.74-1.09, P=0.261)$.

\section{Stratification analysis}

Further investigation was done on the potential association between $X P C$ rs $2228000 \mathrm{C}>\mathrm{T}$ polymorphism and the risk of gastric cancer in the stratified study by age, sex, smoking status, pack-year, drinking status, tumor sites, and TNM stages. The results of stratified analysis are shown in Table 3. The rs2228000 CT/TT genotypes were found to be associated with a significantly decreased risk of gastric cancer among individuals older than 58 (adjusted $\mathrm{OR}=0.67$, 95\% CI $=0.46-0.97$ ), when CC genotype served as a reference. Similarly, when compared with noncarriers, carriers of rs2228000 CT/TT genotypes had a significantly decreased risk of gastric cancer among nondrinkers (crude $\mathrm{OR}=0.80$, $95 \%$ CI $=0.65-0.99$ ). Statistical significance of the association was reevaluated after adjustment for age, sex, smoking, and drinking status, and the protective effect of rs2228000 CT/TT genotypes against gastric cancer was not observed. Moreover, no significant association between gastric cancer risk and rs2228000 genotypes was observed in the stratified analyses by sex, smoking status, pack-year, tumor sites, and TNM stages. 
Table 2 Association between XPC gene polymorphisms and gastric cancer risk

\begin{tabular}{|c|c|c|c|c|c|c|c|}
\hline Genotypes & Cases, n (\%) & Controls, n (\%) & $P$-value ${ }^{a}$ & OR $(95 \% \mathrm{Cl})$ & $P$-value & Adjusted OR $(95 \% \mathrm{Cl})$ & $P$-value ${ }^{b}$ \\
\hline \multicolumn{8}{|l|}{$r s 222800$ I $A>C$} \\
\hline AA & $460(40.3)$ & $472(40.2)$ & & 1.00 & & 1.00 & \\
\hline$A C$ & $534(46.8)$ & $557(47.5)$ & & $0.98(0.83-1.17)$ & 0.854 & $1.03(0.85-1.26)$ & 0.756 \\
\hline $\mathrm{CC}$ & I 48 (|3.0) & 144 (12.3) & & $1.06(0.8 \mathrm{I}-1.37)$ & 0.692 & $1.06(0.79-1.42)$ & 0.712 \\
\hline Dominant & $682(59.7)$ & 701 (59.8) & 0.984 & $1.00(0.85-1.18)$ & 0.984 & $1.04(0.86-1.25)$ & 0.703 \\
\hline Additive model & & & 0.870 & $1.01(0.90-1.15)$ & 0.818 & $1.03(0.90-1.18)$ & 0.679 \\
\hline Recessive & $994(87.0)$ & $\mathrm{I}, 029(87.7)$ & 0.620 & $1.06(0.83-1.36)$ & 0.620 & $1.04(0.79-1.37)$ & 0.783 \\
\hline \multicolumn{8}{|l|}{ rs $2228000 \mathrm{C}>\mathrm{T}$} \\
\hline $\mathrm{CC}$ & $457(40.0)$ & $429(36.6)$ & & 1.00 & & 1.00 & \\
\hline $\mathrm{CT}$ & $524(45.9)$ & $583(49.7)$ & & $0.84(0.7 \mathrm{I}-\mathrm{I} .0 \mathrm{I})$ & 0.060 & $0.89(0.72-1.08)$ & 0.231 \\
\hline TT & $161(14.1)$ & $161(13.7)$ & & $0.94(0.73-\mid .21)$ & 0.627 & $0.94(0.70-1.25)$ & 0.666 \\
\hline Dominant & $685(60.0)$ & $744(63.4)$ & 0.088 & $0.86(0.73-1.02)$ & 0.088 & $0.90(0.74-1.09)$ & $0.26 \mathrm{I}$ \\
\hline Additive model & & & 0.164 & $0.94(0.83-1.06)$ & 0.278 & $0.95(0.83-1.09)$ & 0.431 \\
\hline Recessive & 981 (85.9) & $1,012(86.3)$ & 0.796 & $1.03(0.82-1.31)$ & 0.796 & $1.01(0.77-1.31)$ & 0.973 \\
\hline \multicolumn{8}{|l|}{ rs $2607775 \mathrm{C}>\mathrm{G}$} \\
\hline $\mathrm{CC}$ & $\mathrm{I}, 05 \mathrm{I}(92.0)$ & $1,079(92.0)$ & & 1.00 & & 1.00 & \\
\hline CG & $87(7.6)$ & 91 (7.8) & & $0.98(0.72-1.33)$ & 0.905 & $0.94(0.66-1.33)$ & 0.708 \\
\hline GG & $4(0.4)$ & $3(0.3)$ & & $1.37(0.31-6.12)$ & 0.683 & $0.57(0.11-3.15)$ & 0.508 \\
\hline Dominant & $91(8.0)$ & $94(8.0)$ & 0.968 & $0.99(0.74-1.34)$ & 0.968 & $0.92(0.65-1.30)$ & 0.625 \\
\hline Additive model & & & 0.911 & $1.01(0.76-1.34)$ & 0.967 & $0.91(0.65-1.26)$ & 0.558 \\
\hline Recessive & I, 138 (99.6) & I, I 70 (99.7) & 0.679 & $1.37(0.31-6.13)$ & 0.682 & $0.57(0.11-3.17)$ & 0.512 \\
\hline \multicolumn{8}{|l|}{$r s|870| 34 G>C$} \\
\hline GG & 711 (62.3) & $742(63.3)$ & & 1.00 & & 1.00 & \\
\hline GC & $378(33.1)$ & 374 (31.9) & & $1.06(0.88-1.26)$ & 0.553 & 1.05 & 0.606 \\
\hline $\mathrm{CC}$ & $53(4.6)$ & 57 (4.9) & & $0.97(0.66-1.43)$ & 0.879 & $0.95(0.6 \mathrm{I}-1.47)$ & 0.819 \\
\hline Dominant & $431(37.7)$ & $431(36.7)$ & 0.620 & $1.04(0.88-1.24)$ & 0.620 & $1.04(0.86-1.26)$ & 0.688 \\
\hline Additive model & & & 0.813 & $1.02(0.89-1.18)$ & 0.747 & $1.02(0.87-1.19)$ & 0.828 \\
\hline Recessive & I,089 (95.4) & I,I I $6(95.1)$ & 0.805 & $0.95(0.65-1.40)$ & 0.805 & $0.93(0.61-1.44)$ & 0.755 \\
\hline
\end{tabular}

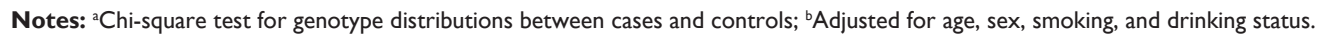

Abbreviations: $\mathrm{Cl}$, confidence interval; $\mathrm{OR}$, odds ratio.

Table 3 Stratification analysis for association between XPC rs2228000 C > T genotypes and gastric cancer risk

\begin{tabular}{|c|c|c|c|c|c|c|}
\hline \multirow[t]{2}{*}{ Variables } & \multicolumn{2}{|c|}{$\begin{array}{l}\text { rs2228000 C }>\mathrm{T} \\
\text { (cases/controls) }\end{array}$} & \multirow[t]{2}{*}{ OR (95\% Cl) } & \multirow[t]{2}{*}{$P$-value } & \multirow[t]{2}{*}{$\begin{array}{l}\text { Adjusted OR } \\
(95 \% \mathrm{Cl})\end{array}$} & \multirow[t]{2}{*}{$P$-value } \\
\hline & $\overline{C C}$ & $\overline{\mathrm{CT} / \mathrm{TT}}$ & & & & \\
\hline \multicolumn{7}{|c|}{ Median age, years } \\
\hline$\leq 58$ & $224 / 377$ & $377 / 639$ & $0.99(0.80-1.21)$ & 0.888 & $0.98(0.79-1.22)$ & $0.84 I$ \\
\hline$>58$ & $233 / 52$ & $311 / 105$ & $0.66(0.46-0.96)$ & 0.030 & $0.67(0.46-0.97)$ & 0.034 \\
\hline \multicolumn{7}{|l|}{ Sex } \\
\hline Male & $307 / 293$ & $442 / 496$ & $0.85(0.69-1.04)$ & 0.122 & $0.90(0.7 \mid-1.14)$ & 0.390 \\
\hline Female & $150 / 136$ & $243 / 248$ & $0.89(0.66-1.19)$ & 0.427 & $0.88(0.64-I .2 I)$ & 0.433 \\
\hline \multicolumn{7}{|l|}{ Smoking status } \\
\hline Never & $293 / 238$ & $442 / 424$ & $0.85(0.68-1.05)$ & 0.133 & $0.86(0.67-1.1 I)$ & 0.240 \\
\hline Ever & $164 / 191$ & $243 / 320$ & $0.88(0.68-1.16)$ & 0.367 & $0.93(0.69-1.26)$ & 0.646 \\
\hline \multicolumn{7}{|l|}{ Pack-year } \\
\hline 0 & $293 / 238$ & $442 / 424$ & $0.85(0.68-1.05)$ & 0.133 & $0.86(0.67-1.11)$ & 0.240 \\
\hline$\leq 30$ & $106 / 150$ & $166 / 233$ & $1.01(0.73-1.39)$ & 0.960 & $1.04(0.7|-| .5 I)$ & 0.844 \\
\hline$>30$ & $58 / 41$ & $77 / 87$ & $0.63(0.38-1.04)$ & 0.068 & $0.73(0.42-1.25)$ & 0.245 \\
\hline \multicolumn{7}{|l|}{ Drinking status } \\
\hline Never & $375 / 210$ & $559 / 390$ & $0.80(0.65-0.99)$ & 0.043 & $0.85(0.68-1.07)$ & 0.171 \\
\hline Ever & $82 / 219$ & $126 / 354$ & $0.95(0.69-1.32)$ & 0.760 & $0.92(0.63-1.34)$ & 0.649 \\
\hline \multicolumn{7}{|l|}{ Tumor sites } \\
\hline Cardia & $99 / 429$ & $|4| / 744$ & $0.82(0.62-1.09)$ & 0.173 & $0.87(0.63-1.20)$ & 0.386 \\
\hline Non-cardia & $358 / 429$ & $544 / 744$ & $0.88(0.73-1.05)$ & 0.147 & $0.88(0.72-1.08)$ & 0.216 \\
\hline \multicolumn{7}{|l|}{ TNM stages } \\
\hline $\mathrm{I} / \mathrm{II}$ & $175 / 429$ & $294 / 744$ & $0.97(0.78-\mid .2 I)$ & 0.778 & $0.95(0.74-1.22)$ & 0.695 \\
\hline III/IV & $282 / 429$ & $391 / 744$ & $0.80(0.66-0.97)$ & 0.024 & $0.83(0.67-1.04)$ & 0.101 \\
\hline
\end{tabular}

Notes: a Obtained in logistic regression models with adjustment for age, sex, smoking, and drinking status. Results in bold are significant findings.

Abbreviations: $\mathrm{Cl}$, confidence interval; OR, odds ratio. 


\section{Discussion}

In this study, a large scale case-control study was performed to investigate the associations between four potentially functional SNPs in the $X P C$ gene and the risk of gastric cancer in a Southern Chinese population. The results showed that none of the four polymorphisms in the $X P C$ gene had a significant main effect on the risk of developing gastric cancer. However, compared with CC genotype, the rs $2228000 \mathrm{CT} / \mathrm{TT}$ genotypes carriers were associated with a borderline decreased risk of gastric cancer and this protective effect against gastric cancer was more evident among individuals older than 58 years of age. It was worth noting that the increased protective effect in the older group might be ascribed to the reduction of sample sizes. To the best of the authors' knowledge, by far, this is the largest study to investigate the association of the four XPC SNPs with gastric cancer risk.

The $X P C$ gene is located at chromosome $3 \mathrm{p} 25$ containing 16 exons and 15 introns. It encodes a 940-amino acid protein that can form a XPC-RAD23B complex through the interaction with RAD23B. ${ }^{24}$ In the process of NER, the XPC-HR23B complex first recognizes the DNA damage site and then recruits the transcription factor IIH helicases ERCC2/XPD and ERCC3/XPB to open the DNA strands surrounding the site of the lesion. ${ }^{18,25}$ The binding of XPC to damaged DNA is the rate-limiting step for NER. ${ }^{26} \mathrm{Sub}-$ sequently, a multiprotein factor composed of XPA and the single-strand DNA-binding protein replication protein A are then recruited to the opened structure near the lesion to verify the damage-specific localization of repair complexes or to assure the correct 3D assembly. ${ }^{25}$ Finally, the open DNA complex creates the substrate for cleavage by two structure-specific endonucleases ERCC1-XPF ${ }^{27}$ and XPG. ${ }^{28}$ Many polymorphisms that were detected in $X P C$ gene may change the DNA repair capacity, and thus contribute to cancer susceptibility. ${ }^{29,30}$ These variants may modulate susceptibility to gastric cancer through the complex gene-gene and geneenvironment interactions.

Although a few studies have investigated the role of $X P C$ polymorphisms in gastric cancer, inconsistent results have been reported. In a hospital-based case-control study consisting of 106 cases and 116 controls in Turkish population, no association between XPC Lys939Gln (rs2228001) polymorphism and susceptibility to gastric cancer was observed..$^{31}$ Long et al also found the null association between XPC Lys939Gln and gastric cancer risk in a Chinese population. ${ }^{32}$ In contrast, other studies reported opposite results regarding the association. In a study of 496 Japanese gastric cancer patients, the $X P C$ rs2228000 TT genotype was associated with shorter overall survival and recurrence-free survival, compared with $\mathrm{CC} / \mathrm{CT}$ genotypes. ${ }^{33}$ Lately, Xue et al reported that XPC rs2228001 had no statistical association with response to chemotherapy in 410 gastric cancer patients recruited from People's Republic of China. ${ }^{34}$ In a meta-analysis consisting of 1,355 gastric cancer cases and 2,753 controls from six studies, Peng et al found that there were no association between three $X P C$ polymorphisms (Lys939Gln (rs2228001 A $>$ C), Val499Arg (rs2228000 C $>\mathrm{T}$ ), and $\mathrm{PAT}^{-/+}$) and gastric cancer risk in the overall and subgroup analyses. ${ }^{35}$ The discrepancies among studies might be partly due to tumor specificity, ethnic and demographic differences, or insufficient statistical power resulting from a small sample size. For example, the frequency of the rs $2228001 \mathrm{C}$ allele was 0.36 in Chinese populations in the current study, 0.38 in Swedish population, ${ }^{36}$ and 0.55 in Turkish population in the study by Engin et al. ${ }^{31}$

Given the critical role of the $X P C$ gene in the NER pathway, it is biologically plausible that functional $X P C$ variants may alter the DNA repair capacity of NER, and thereby modify the risk of gastric cancer. In this study, no significant association was observed between variant genotypes of $X P C$ polymorphisms and gastric cancer risk in the overall analysis. The following reasons may help to explain the negative observation. First, gastric cancer is a multifactorial disease resulting from complex interactions between environmental and genetic factors. ${ }^{37}$ Variants at a single locus may moderately contribute to risk of cancer due to their weak penetrance. Second, the true associations of $X P C$ gene polymorphisms with gastric cancer might be covered by the other seven core genes (ie, $X P A, X P B, X P D$, $X P E, X P F, X P G$, and $E R C C 1$ ), because variants in these genes may interfere with each other while modifying the DNA repair capacity of NER.

Although four potentially functional SNPs were extensively analyzed in the $X P C$ gene in a large case-control study, some limitations should be noted when interpreting the findings. First, frequency matching between cases and controls in this research was only performed on sex, but not on age, smoking, and drinking status. Multivariate logistic regression analysis was used to reduce the impact of these factors to some extent but not adequately. Second, other risk factors, such as dietary intake, occupational exposure, $H$. pylori infection status, and environmental factors, should be considered. Lack of these data might affect the reliability of the results as gastric cancer is a heterogeneous disease. Third, the selection of SNPs in this study is based on database searching. Although these four SNPs genotyped in this study can 
represent all potentially functional SNPs with minor allele frequency $>0.5$ recorded in HapMap database, it should be noted that some SNPs not recorded in the database may be omitted. Future studies containing more SNPs in the XPC gene are needed. Fourth, survival data were not available for the present study, which limited the survival analysis in the current study. Finally, this study was a hospital-based casecontrol study with subjects from South China, which may not well represent other Chinese populations in a different region. As a result, selection bias is inevitable.

In conclusion, it was found that the $X P C \mathrm{rs} 2228001 \mathrm{~A}>\mathrm{C}$, rs2228000 C $>$ T, rs2607775 $\mathrm{C}>\mathrm{G}$, and rs1870134 $\mathrm{G}>\mathrm{C}$ polymorphisms were not associated with gastric cancer susceptibility. Well designed, prospective studies with a larger sample size, involving different ethnicities, are warranted to clarify the role of these polymorphisms in the future.

\section{Acknowledgments}

This study was supported by grants from the National Natural Science Foundation of China (Grant No 81502046), Special Financial Grant from the China Postdoctoral Science Foundation(Grant No 2014T70836), the Natural Science Foundation of Guangdong Province (Grant No 2015A030310324), and the National Science Fund for Distinguished Young Scholars (Grant No 81325018).

\section{Disclosure}

The authors report no conflicts of interest in this work.

\section{References}

1. Torre LA, Bray F, Siegel RL, Ferlay J, Lortet-Tieulent J, Jemal A. Global cancer statistics, 2012. CA Cancer J Clin. 2015;65(2):87-108.

2. Zeng H, Zheng R, Guo Y, et al. Cancer survival in China, 2003-2005: a population-based study. Int J Cancer. 2015;136(8):1921-1930.

3. Vogiatzi P, Vindigni C, Roviello F, Renieri A, Giordano A. Deciphering the underlying genetic and epigenetic events leading to gastric carcinogenesis. J Cell Physiol. 2007;211(2):287-295.

4. Abnet CC, Freedman ND, Hu N, et al. A shared susceptibility locus in PLCE1 at 10q23 for gastric adenocarcinoma and esophageal squamous cell carcinoma. Nat Genet. 2010;42(9):764-767.

5. Chow WH, Blot WJ, Vaughan TL, et al. Body mass index and risk of adenocarcinomas of the esophagus and gastric cardia. J Natl Cancer Inst. 1998;90(2):150-155.

6. Zhang ZF, Kurtz RC, Yu GP, et al. Adenocarcinomas of the esophagus and gastric cardia: the role of diet. Nutr Cancer. 1997;27(3):298-309.

7. Moy KA, Fan Y, Wang R, Gao YT, Yu MC, Yuan JM. Alcohol and tobacco use in relation to gastric cancer: a prospective study of men in Shanghai, China. Cancer Epidemiol Biomarkers Prev. 2010;19(9):2287-2297.

8. Wadhwa R, Song S, Lee JS, Yao Y, Wei Q, Ajani JA. Gastric cancermolecular and clinical dimensions. Nat Rev Clin Oncol. 2013;10(11): 643-655.

9. He J, Qiu LX, Wang MY, et al. Polymorphisms in the XPG gene and risk of gastric cancer in Chinese populations. Hum Genet. 2012;131(7): $1235-1244$.
10. He J, Xu Y, Qiu LX, et al. Polymorphisms in ERCC1 and XPF genes and risk of gastric cancer in an eastern Chinese population. PLoS One. 2012;7(11):e49308.

11. He J, Wang MY, Qiu LX, et al. Genetic variations of mTORC1 genes and risk of gastric cancer in an Eastern Chinese population. Mol Carcinog. 2013;52(Suppl 1):E70-E79.

12. Wang MY, He J, Zhu ML, et al. A Functional Polymorphism (rs2494752) in the AKT1 Promoter Region and Gastric Adenocarcinoma Risk in an Eastern Chinese Population. Sci Rep. 2016;6:20008.

13. Wood RD, Mitchell M, Sgouros J, Lindahl T. Human DNA repair genes. Science. 2001;291(5507):1284-1289.

14. De Silva IU, McHugh PJ, Clingen PH, Hartley JA. Defining the roles of nucleotide excision repair and recombination in the repair of DNA interstrand cross-links in mammalian cells. Mol Cell Biol. 2000;20(21): 7980-7990

15. Cordonnier AM, Fuchs RP. Replication of damaged DNA: molecular defect in xeroderma pigmentosum variant cells. Mutat Res. 1999;435(2): 111-119.

16. Cleaver JE. Common pathways for ultraviolet skin carcinogenesis in the repair and replication defective groups of xeroderma pigmentosum. J Dermatol Sci. 2000;23(1):1-11.

17. Sugasawa K, Ng JM, Masutani C, et al. Xeroderma pigmentosum group $\mathrm{C}$ protein complex is the initiator of global genome nucleotide excision repair. Mol Cell. 1998;2(2):223-232.

18. Yokoi M, Masutani C, Maekawa T, Sugasawa K, Ohkuma Y, Hanaoka F. The xeroderma pigmentosum group C protein complex XPC-HR23B plays an important role in the recruitment of transcription factor IIH to damaged DNA. J Biol Chem. 2000;275(13):9870-9875.

19. Dai QS, Hua RX, Zhang R, et al. Poly (AT) deletion/insertion polymorphism of the XPC gene contributes to urinary system cancer susceptibility: a meta-analysis. Gene. 2013;528(2):335-342.

20. He J, Shi TY, Zhu ML, Wang MY, Li QX, Wei QY. Associations of Lys939Gln and Ala499Val polymorphisms of the XPC gene with cancer susceptibility: a meta-analysis. Int J Cancer. 2013;133(8): $1765-1775$.

21. Dai QS, Hua RX, Zeng RF, Long JT, Peng ZW. XPC gene polymorphisms contribute to bladder cancer susceptibility: a meta-analysis. Tumour Biol. 2014;35(1):447-453.

22. Zhu ML, Hua RX, Zheng L. Associations between polymorphisms of the XPC gene and lung cancer susceptibility: a meta-analysis. Tumour Biol. 2014;35(4):2931-2939.

23. Washington K. 7th edition of the AJCC cancer staging manual: stomach. Ann Surg Oncol. 2010;17(12):3077-3079.

24. Khan SG, Muniz-Medina V, Shahlavi T, et al. The human XPC DNA repair gene: arrangement, splice site information content and influence of a single nucleotide polymorphism in a splice acceptor site on alternative splicing and function. Nucleic Acids Res. 2002;30(16): 3624-3631.

25. Missura M, Buterin T, Hindges R, et al. Double-check probing of DNA bending and unwinding by XPA-RPA: an architectural function in DNA repair. EMBO J. 2001;20(13):3554-3564.

26. Janicijevic A, Sugasawa K, Shimizu Y, et al. DNA bending by the human damage recognition complex XPC-HR23B. DNA Repair (Amst). 2003;2(3):325-336.

27. Sijbers AM, de Laat WL, Ariza RR, et al. Xeroderma pigmentosum group F caused by a defect in a structure-specific DNA repair endonuclease. Cell. 1996;86(5):811-822.

28. O'Donovan A, Davies AA, Moggs JG, West SC, Wood RD. XPG endonuclease makes the 3' incision in human DNA nucleotide excision repair. Nature. 1994;371(6496):432-435.

29. Khan SG, Metter EJ, Tarone RE, et al. A new xeroderma pigmentosum group C poly(AT) insertion/deletion polymorphism. Carcinogenesis. 2000;21(10):1821-1825.

30. Dong Z, Guo W, Zhou R, et al. Polymorphisms of the DNA repair gene $\mathrm{XPA}$ and XPC and its correlation with gastric cardiac adenocarcinoma in a high incidence population in North China. J Clin Gastroenterol. 2008;42(8):910-915. 
31. Engin AB, Karahalil B, Engin A, Karakaya AE. DNA repair enzyme polymorphisms and oxidative stress in a Turkish population with gastric carcinoma. Mol Biol Rep. 2011;38(8):5379-5386.

32. Long XD, Ma Y, Huang YZ, et al. Genetic polymorphisms in DNA repair genes XPC, XPD, and XRCC4, and susceptibility to Helicobacter pylori infection-related gastric antrum adenocarcinoma in Guangxi population, China. Mol Carcinog. 2010;49(6):611-618.

33. Li Y, Liu Z, Liu H, et al. Potentially functional variants in the core nucleotide excision repair genes predict survival in Japanese gastric cancer patients. Carcinogenesis. 2014;35(9):2031-2038.

34. Xue MH, Li GY, Wu XJ, Zhang CX, Zhang CF, Zhu KX. Genetic variability of genes in NER pathway influences the treatment outcome of gastric cancer. Int J Clin Exp Pathol. 2015;8(5):5563-5569.
35. Peng Q, Chen Z, Lu Y, et al. Current evidences on XPC polymorphisms and gastric cancer susceptibility: a meta-analysis. Diagn Pathol. 2014;9:96.

36. Ye W, Kumar R, Bacova G, Lagergren J, Hemminki K, Nyren O. The XPD 751Gln allele is associated with an increased risk for esophageal adenocarcinoma: a population-based case-control study in Sweden Carcinogenesis. 2006;27(9):1835-1841.

37. Guan Z, Zhang J, Song S, Dai D. Promoter methylation and expression of TIMP3 gene in gastric cancer. Diagn Pathol. 2013;8:110.

\section{Publish your work in this journal}

OncoTargets and Therapy is an international, peer-reviewed, open access journal focusing on the pathological basis of all cancers, potential targets for therapy and treatment protocols employed to improve the management of cancer patients. The journal also focuses on the impact of management programs and new therapeutic agents and protocols on

\section{Dovepress}

patient perspectives such as quality of life, adherence and satisfaction. The manuscript management system is completely online and includes a very quick and fair peer-review system, which is all easy to use. Visit http://www.dovepress.com/testimonials.php to read real quotes from published authors.

Submit your manuscript here: http://www.dovepress.com/oncotargets-and-therapy-journal 